\title{
The Use of Bone Marrow Stromal Cells (Bone Marrow-Derived Multipotent Mesenchymal Stromal Cells) for Alveolar Bone Tissue Engineering: Basic Science to Clinical Translation
}

\author{
Hideaki Kagami, DDS, PhD, ${ }^{1-3}$ Hideki Agata, DDS, PhD, ${ }^{4}$ Minoru Inoue, DDS, PhD, ${ }^{1,2}$ Izumi Asahina, DDS, PhD, ${ }^{4}$ \\ Arinobu Tojo, MD, PhD, Naohide Yamashita, MD, PhD, ${ }^{2}$ and Kohzoh Imai, MD, PhD ${ }^{5}$
}

Bone tissue engineering is a promising field of regenerative medicine in which cultured cells, scaffolds, and osteogenic inductive signals are used to regenerate bone. Human bone marrow stromal cells (BMSCs) are the most commonly used cell source for bone tissue engineering. Although it is known that cell culture and induction protocols significantly affect the in vivo bone forming ability of BMSCs, the responsible factors of clinical outcome are poorly understood. The results from recent studies using human BMSCs have shown that factors such as passage number and length of osteogenic induction significantly affect ectopic bone formation, although such differences hardly affected the alkaline phosphatase activity or gene expression of osteogenic markers. Application of basic fibroblast growth factor helped to maintain the in vivo osteogenic ability of BMSCs. Importantly, responsiveness of those factors should be tested under clinical circumstances to improve the bone tissue engineering further. In this review, clinical application of bone tissue engineering was reviewed with putative underlying mechanisms.

\section{Introduction}

A TROPHIC ALVEOLAR BONE is one of the major obstacles for dental implant therapy and there are a large number of patients without sufficient bone volume. For patients with severe bone atrophy, autologous bone grafts have been performed. ${ }^{1}$ However, even the amount of harvesting bone is small, the procedure is accompanied by swelling and pain of the donor site. ${ }^{2}$ Although bioartificial bone substitutes have been frequently used, the ability to induce bone is limited. ${ }^{3}$ Accordingly, less invasive and more efficient bone regeneration therapy is awaited, such as tissue engineering.

The first results of clinical bone tissue engineering were published in 2001. ${ }^{4}$ In this study, the regeneration of long bone defects was tested using hydroxyapatite blocks together with cultured autologous bone marrow stromal cells (BMSCs). This tissue engineering-based approach proved the feasibility of this concept. The results from a preliminary clinical study of alveolar bone regeneration were published thereafter. ${ }^{5}$ In this review, studies on clinical alveolar bone tissue engineering are summarized. Then, the problems associated with current tissue engineering were also discussed.

\section{Bone Tissue Engineering and Stem Cells}

Cells are considered as a major component of tissue engineering. Although the role of transplanted cells during bone tissue regeneration is still controversial, it has been proved that the transplanted cells could survive, proliferate, and differentiate into osteogenic phenotype. ${ }^{6}$ There is accumulating evidence that the level and quality of regeneration is affected by the ability of transplanted cells. ${ }^{7}$ Accordingly, it is important to establish an optimal cell culture protocol to maximize the function of osteogenic cells. Surprisingly, the BMSC ability to differentiate into osteoblast-like cells is easily diminished during passage and no bone formation was observed after several passages (Fig. 1). ${ }^{7,8}$ Furthermore, cell seeding density and the period of induction also affect in vivo osteogenic ability. It has been

\footnotetext{
${ }^{1}$ Tissue Engineering Research Group, Division of Molecular Therapy, The Advanced Clinical Research Center, The Institute of Medical Science, The University of Tokyo, Tokyo, Japan.

${ }^{2}$ Department of Advanced Medical Science, Clinic for Bone Regeneration, IMSUT Hospital, The Institute of Medical Science, The University of Tokyo, Tokyo, Japan.

${ }^{3}$ Department of Oral and Maxillofacial Surgery, Matsumoto Dental University Dental School, Shiojiri, Japan.

${ }^{4}$ Unit of Translational Medicine, Department of Regenerative Oral Surgery, Nagasaki University Graduate School of Biomedical Sciences, Nagasaki, Japan.

${ }^{5}$ Center for Antibody and Vaccine, IMSUT Hospital, The Institute of Medical Science, The University of Tokyo, Tokyo, Japan.
} 
FIG. 1. Effect of passage number on ectopic in vivo osteogenic ability. Upper panels showing ectopic bone formation at the back of nude mice with tissue-engineered bone using passage 1 (a) and passage 5 (b) human bone marrow stromal cells (BMSCs). The success of ectopic bone formation quickly decrease after passage and no bone formation was observed after passage 4 (c). Note that the ability is quickly lost during passage. Modified from Agata et al. ${ }^{7}$ Color images available online at www.liebertpub .com/teb

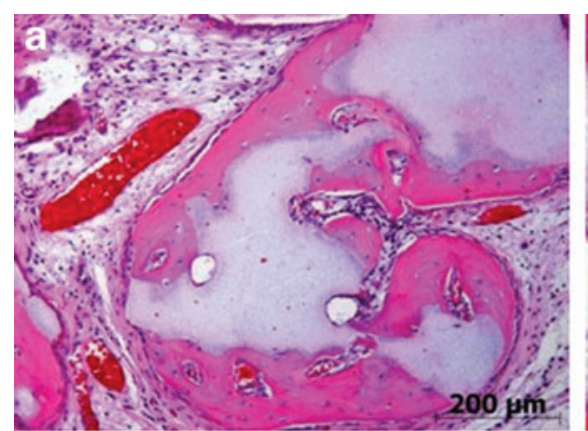

Passage 1

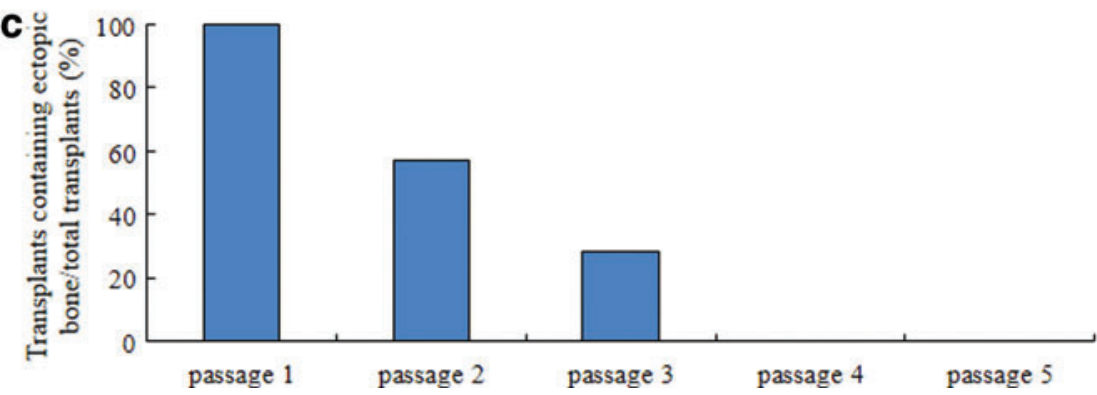

shown that basic fibroblast growth factor (bFGF) is beneficial to maintain in vivo osteogenic ability of BMSCs. ${ }^{7}$

\section{Clinical Studies on Alveolar Bone Tissue Engineering}

The results from clinical studies on alveolar bone tissue engineering using BMSCs were first reported in 2004. In this study, bone marrow-derived MSCs were mixed with platelet-rich plasma as a scaffold. ${ }^{8}$ Bone regeneration was observed in all moderate atrophy cases. Another clinical study utilized BMSCs and hydroxyapatite granules. BMSCs were induced into osteogenic cells for 1 week and transplanted. In this study, bone formation was observed in three cases, but there was no apparent bone formation from the

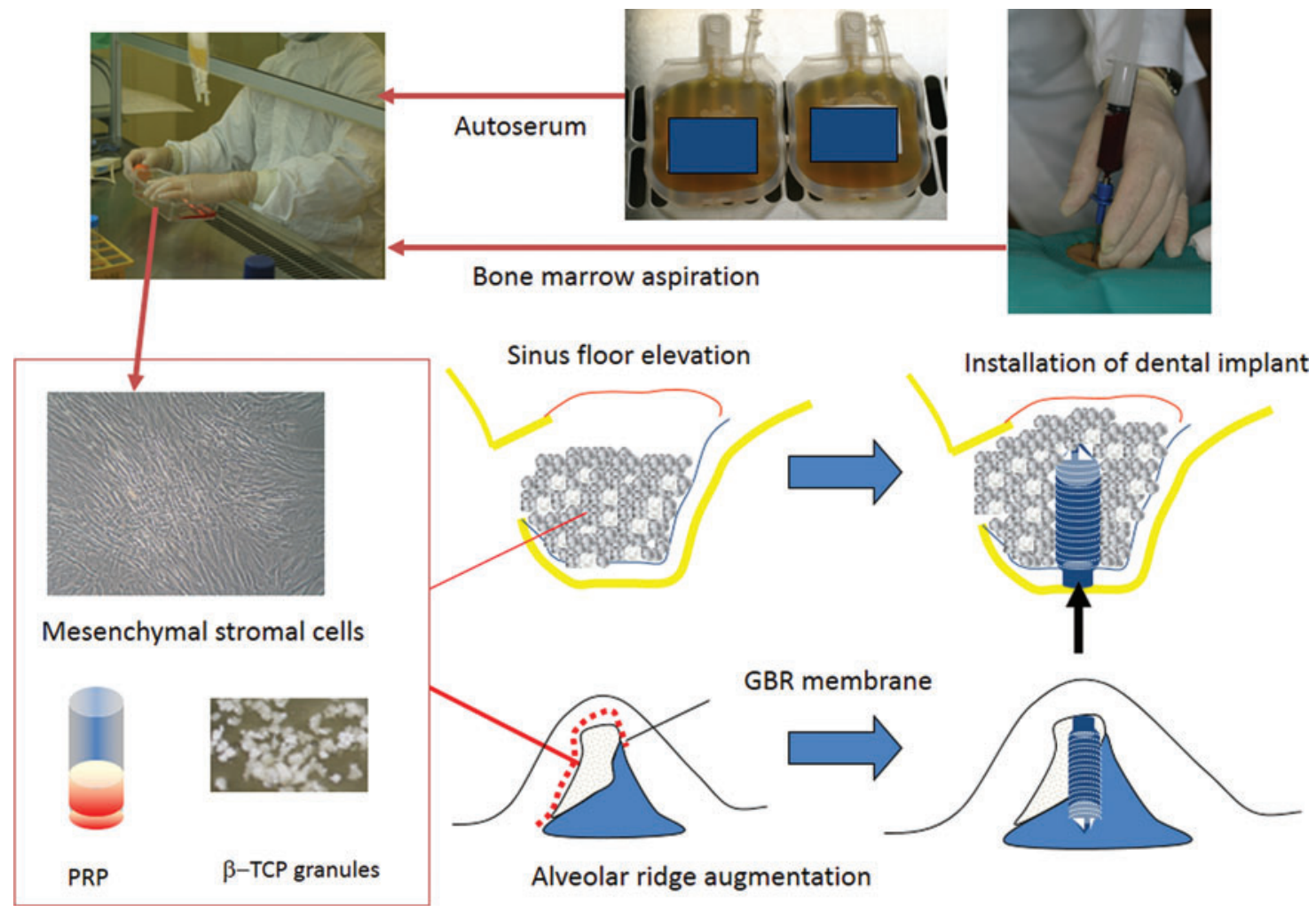

FIG. 2. The procedure for clinical study of alveolar bone regeneration at IMSUT Hospital, The Institute of Medical Science, The University of Tokyo. $\beta$-TCP, beta-tricalcium phosphate; PRP, platelet rich plasma. Color images available online at www .liebertpub.com/teb 

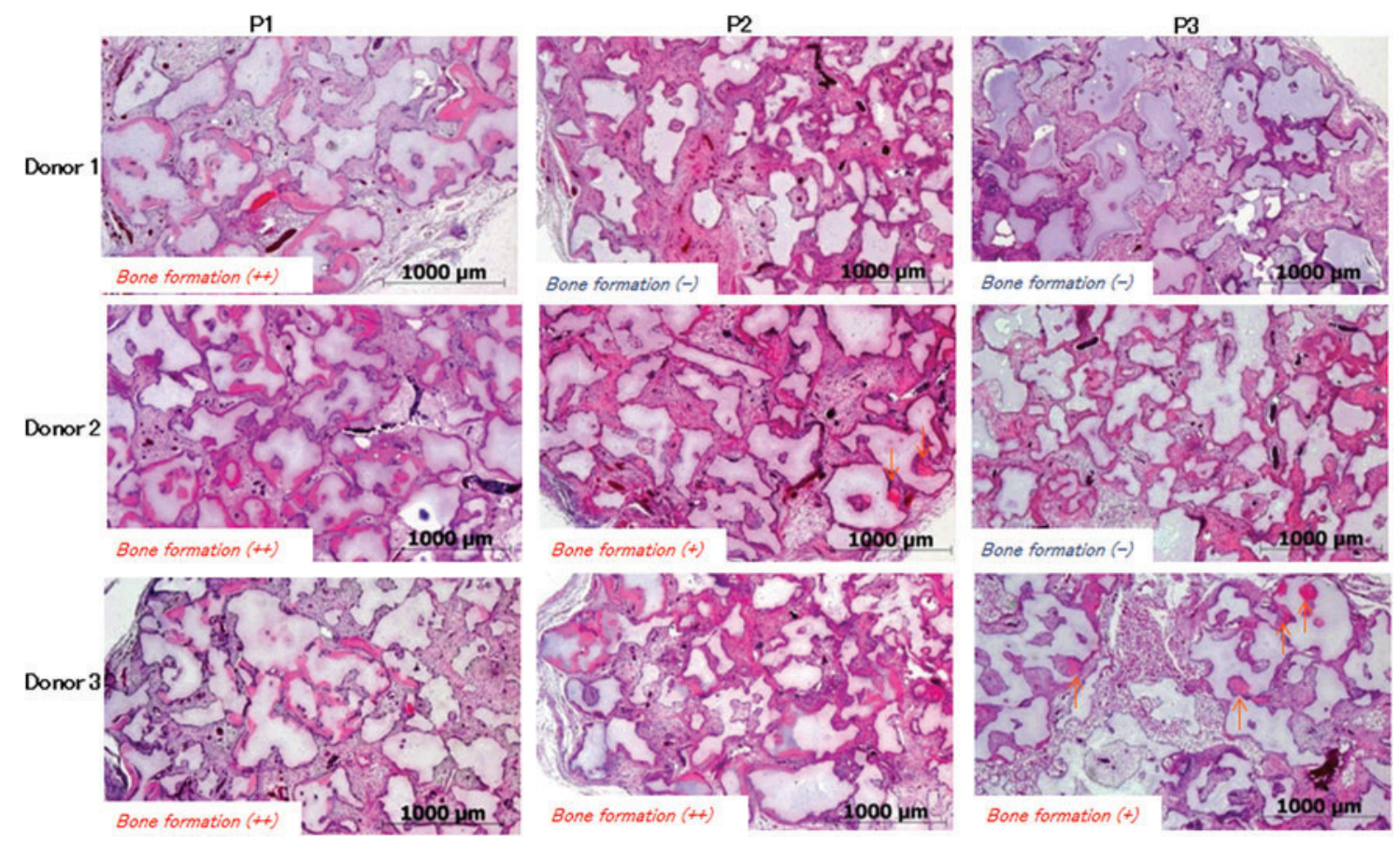

FIG. 3. Individual (donor) variations of in vivo osteogenic ability and their changes during passage. Note that the effect of passage differed between individuals. Modified from Agata. ${ }^{9}$ Color images available online at www.liebertpub.com/teb

transplanted cells in cases where the atrophy was severe. Thus, the efficacy of clinical alveolar bone tissue engineering for severe atrophy cases remains controversial.

We have conducted a clinical study of bone tissue engineering for severe atrophy of alveolar bone. In this study, autologous BMSCs were transplanted together with plateletrich plasma gel and beta-tricalcium phosphate ( $\beta$-TCP) granules as scaffolds (Fig. 2). The results from a 2-year observation showed that bone regeneration was observed in all patients, although significant individual variations in cell growth, differentiation, and levels of bone regeneration were observed (Asahina et al., manuscript in preparation). This type of study, focused on severe atrophy cases, may prove the usefulness of alveolar bone tissue engineering. In terms of safety, no side effects or related complications have been reported, which may imply the relatively safety nature of alveolar bone tissue engineering using BMSCs.

\section{Toward the Establishment of Reliable Alveolar Bone Tissue Engineering Using BMSCs}

Although clinical studies have confirmed the feasibility and safety of alveolar bone tissue engineering using BMSCs, one of the important clinical benchmarks is the efficacy for severe atrophy cases. The results from focused studies with selected cases will provide the evidence. Another important problem is the individual variation as shown by basic and preliminary clinical studies. Since the shape and the size of bone defect vary among individuals, it might be impossible to completely eliminate such variations. Accordingly, it should be important to minimize the variation in other factors, such as cells. In terms for BMSCs, there was no significant difference in the expression of mesenchymal stem cell markers during passage. ${ }^{7}$ In contrast, a large variation was observed in the in vivo bone forming ability among donors and during passage (Fig. 3). ${ }^{7,8,9} \mathrm{We}$ believe the usage of early passage cells as well as growth factors (bFGF) may minimize the variation, which should be tested under clinical settings.

In spite of the number of studies and the clinical efficacy of bone tissue engineering, it is not a standard treatment at present. It is necessary to show the superiority of clinical outcome compared with standard autologous bone transplantation and allogenic (or xenogenic) transplantation. Furthermore, tissue engineering requires special facility for cell culture and there is a requirement for many safety examinations, which may also increase the cost for treatment. Those technologies, which may support the widespread use of bone tissue engineering, should be investigated.

Tissue engineering is one of the most rapidly progressing fields and alveolar bone is still an attractive target for tissue engineering. ${ }^{10}$ The application of bone tissue engineering is not limited for dental implants and is successfully applied for other diseases such as nonunion fractures ${ }^{11}$ and alveolar clefts. ${ }^{12,13}$

\section{Disclosure Statement}

No competing financial interests exist.

\section{References}

1. Jensen, S.S., and Terheyden, H. Bone augmentation procedures in localized defects in the alveolar ridge: clinical results with different bone grafts and bone-substitute materials. Int J Oral Maxillofac Implants 24 Suppl, 218, 2009.

2. Clavero, J., and Lundgren, S. Ramus or chin grafts for maxillary sinus inlay and local onlay augmentation: comparison of donor site morbidity and complications. Clin Implant Dent Relat Res 5, 154, 2003. 
3. Becker, W., Urist, M., Becker, B.E., Jackson, W., Parry, D.A., Bartold, M., Vincenzzi, G., De Georges, D., and Niederwanger, M. Clinical and histologic observations of sites implanted with intraoral autologous bone grafts or allografts. 15 human case reports. J Periodontol 67, 1025, 1996.

4. Quatro, R., Mastrogiacomo, M., and Cancedda, R. Repair of large bone defects with the use of autologous bone marrow stromal cells. N Engl J Med 344, 385, 2001.

5. Yamada, Y., Ueda, M., Hibi, H., and Nagasaka, T. Translational research for injectable tissue-engineered bone regeneration using mesenchymal stem cells and platelet-rich plasma: from basic research to clinical case study. Cell Transplant 13, 343, 2004.

6. Meijer, G.J., de Bruijn, J.D., Koole, R., and van Blitterswijk, C.A. Cell based bone tissue engineering in jaw defects. Biomaterials 29, 3053, 2008.

7. Agata, H., Asahina, I., Watanabe, N., Ishii, Y., Kubo, N., Ohshima, S., Yamazaki, M., Tojo, A., and Kagami, H. Characteristic change and loss of in vivo osteogenic abilities of human bone marrow stromal cells during passage. Tissue Eng Part A 16, 663, 2010.

8. Sugiura, F., Kitoh, H., and Ishiguro, N. Osteogenic potential of rat mesenchymal stem cells after several passages. Biochem Biophys Res Commun 316, 233, 2004.

9. Agata, H. Toward establishment of truly reliable protocol for bone tissue Engineering. Regenerative Medicine, 8, 439, 2009. (In Japanese).

10. Egusa, H., Sonoyama, W., Nishimura, M., Atsuta, I., and Akiyama, K. Stem cells in dentistry-Part II: clinical applications. J Prosthodont Res 56, 229, 2012.
11. Shoji, T., Ii, M., Mifune, Y., Matsumoto, T., Kawamoto, A., Kwon, S.M., Kuroda, T., Kuroda, R., Kurosaka, M., and Asahara, T. Local transplantation of human multipotent adiposederived stem cells accelerates fracture healing via enhanced osteogenesis and angiogenesis. Lab Invest 90, 637, 2010.

12. Pradel, W., and Lauer, G. Tissue-engineered bone grafts for osteoplasty in patients with cleft alveolus. Ann Anat 194, 545, 2012.

13. Janssen, N.G., Weijs, W.L., Koole, R., Rosenberg, A.J., and Meijer, G.J. Tissue engineering strategies for alveolar cleft reconstruction: a systematic review of the literature. Clin Oral Investig 18, 219, 2014.

Address correspondence to: Hideaki Kagami, DDS, PhD

Tissue Engineering Research Group Division of Molecular Therapy

The Advanced Clinical Research Center The Institute of Medical Science The University of Tokyo 4-6-1 Shirokanedai Minato-ku Tokyo 108-8639 Japan

E-mail: kagami@ims.u-tokyo.ac.jp

Received: September 15, 2013

Accepted: January 30, 2014

Online Publication Date: March 5, 2014 